\title{
Weight control in older adults with knee osteoarthritis: a qualitative study
}

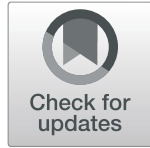

\author{
Wen-Ling Yeh ${ }^{1,2}$, Yun-Fang Tsai ${ }^{3,4,5^{*}}$ (D), Kuo-Yao Hsu ${ }^{2,6}$, Dave Weichih Chen ${ }^{7}$, Jong-Shyan Wang ${ }^{8,9}$ and \\ Ching-Yen Chen ${ }^{2,5}$
}

\begin{abstract}
Background: Knee osteoarthritis (OA) affects mostly older adults and its primary risk factor is obesity. This study sought to understand weight-control strategies, facilitators of and barriers toward weight control in older adults with knee OA who preferred not to undergo physician-recommended total knee arthroplasty.

Methods: For this qualitative descriptive study, older outpatients $(N=118)$ were recruited from orthopedic clinics at three hospitals. Data were collected through face-to face, individual in-depth interviews using a semi-structured interview guide and analyzed using content analysis.

Results: Among participants, only $25.4 \%$ had body weight in the normal range and 55.9\% reported having controlled their weight. Their most common weight-control strategies were to control diet and to exercise and control diet together. Weight control was facilitated by desiring good health, wanting to improve walking or movement, perceiving that they had gained weight, wanting to look good, and advice from healthcare providers. Common barriers to participants' weight control were perceiving that dietary control was not needed, controlling appetite was difficult, dietary control was difficult, and not eating was physically uncomfortable.
\end{abstract}

Conclusions: Our findings help healthcare providers understand how older adults with knee OA perceive weight control and serve as a reference for developing weight-control programs. Health care providers can integrate these identified facilitators and barriers into a weight-control intervention program. The importance of weighing oneself every day, the meaning of body mass index, consulting with a dietician regularly to control weight, and providing appropriate knowledge about aging and weight control should also be included in any weight-control intervention program.

Keywords: Knee osteoarthritis, Older adults, Weight control, Perception

\section{Background}

Osteoarthritis (OA), which is a common joint disorder in the elderly [1], was the 12th leading cause of years lived with disability in 2016 [2]. Knee OA is a major cause of joint pain and problems in daily functioning. These patients' knee pain and physical functioning have

\footnotetext{
* Correspondence: yftsai@mail.cgu.edu.tw

${ }^{4}$ Department of Nursing, Gung University of Science and Technology, Tao-Yuan, Taiwan

${ }^{5}$ Department of Psychiatry, Chang Gung Memorial Hospital at Keelung, Keelung, Taiwan

Full list of author information is available at the end of the article
}

been predicted to deteriorate based on their knee characteristics, clinical factors, and psychosocial factors [3]. Among these factors, obesity is the primary risk factor for knee OA $[4,5]$. Indeed, people clinically defined as obese (body mass index $[\mathrm{BMI}]>30 \mathrm{~kg} / \mathrm{m}^{2}$ ) were four times more likely to have knee OA than those with BMI in a desirable range $\left(\leq 25 \mathrm{~kg} / \mathrm{m}^{2}\right)$ [6]. The degree of obesity in early life was also associated with the risk of developing knee OA later in life [7]. Given population aging and the increasing prevalence of obesity [6], the trend of increasing knee OA prevalence is expected to continue.

(c) The Author(s). 2020 Open Access This article is licensed under a Creative Commons Attribution 4.0 International License, which permits use, sharing, adaptation, distribution and reproduction in any medium or format, as long as you give appropriate credit to the original author(s) and the source, provide a link to the Creative Commons licence, and indicate if changes were made. The images or other third party material in this article are included in the article's Creative Commons licence, unless indicated otherwise in a credit line to the material. If material is not included in the article's Creative Commons licence and your intended use is not permitted by statutory regulation or exceeds the permitted use, you will need to obtain permission directly from the copyright holder. To view a copy of this licence, visit http://creativecommons.org/licenses/by/4.0/ The Creative Commons Public Domain Dedication waiver (http://creativecommons.org/publicdomain/zero/1.0/) applies to the data made available in this article, unless otherwise stated in a credit line to the data. 
Overweight or obese adults with knee OA who participated in behavioral weight-loss interventions in a systematic review and meta-analysis of randomized controlled trials showed moderate improvements in pain and physical function [8]. In other words, disability improved significantly when weight loss was $>5.1 \%$, or a reduction rate of $0.24 \%$ per week [8]. Moreover, all obese/overweight people with $\mathrm{OA}, \geq 45$ years old, with activity-related joint pain, and without morning jointrelated stiffness or morning stiffness lasting $<30 \mathrm{~min}$ are recommended to receive weight-loss treatment [9].

However, such people find weight loss difficult to achieve and maintain [10]. Few studies have addressed the barriers to weight control among patients with knee OA [11-13]. For example, most obese knee-OA outpatients $(89 \%)$ surveyed in the UK had tried to lose weight by changing their diet, trying to exercise more, and joining a support group [11]. Barriers to losing the desired amount of weight were lack of motivation, knee-joint pain, pain in other joints, and lack of time [11]. Similarly, overweight, older Thai adults $(N=40)$ with knee OA who participated in a quadriceps-exercise and weight-management intervention reported not adhering to the weight-management component 6 and 12 months after it ended were mainly family members' and individual eating habits, problems with calorie counts and food-intake record, not preparing meals by oneself, insufficient time to eat, and diet-related health problems [12]. Twenty US patients were interviewed 3 months before $(n=11)$ or after $(n=9)$ knee-replacement surgery regarding their barriers to healthy eating. Their commonly reported barriers were desiring high-fat/high-calorie foods, difficulty managing overeating at restaurants and evening snacks, and difficulty managing negative mood, e.g., stress, depression, boredom [13]. Among these studies, the only common barrier was lack of time.

Those with OA and joint symptoms that greatly affect their quality of life (QOL) and cannot be relieved by non-surgical treatment should consider jointreplacement surgery $[9,14]$. However, surgeries for total joint replacement have long waiting lists in the UK [15], which means that these patients need to bear with their painful joint symptoms and live with lower QOL until the surgery. Moreover, evidence indicates that receiving joint-replacement surgery may not relieve all symptoms for some OA patients $[16,17]$, and $18 \%$ of patients are discontented with the outcome [18]. These contradictory evidence-based results may make it difficult for patients with knee OA to decide what treatment to choose.

Those who do not feel comfortable undergoing total knee arthroplasty (TKA) are challenged by how to relieve pain as well as maintain physical function and QOL. In the past 5 years, many intervention programs for this population have focused on exercise alone [19] or combined exercise and weight control [20-22]. Since diet is influenced by culture and preferences [12], more studies are needed, particularly in Asian cultures, to explore weight control in older adults with knee OA. Understanding this population's perceptions of weight control can help healthcare providers provide suitable information to help them control their weight. Therefore, this study was undertaken to understand the weight-control strategies, facilitators of and barriers to weight control among older Taiwanese adults with knee OA who did not feel comfortable undergoing physicianrecommended TKA.

\section{Methods \\ Design}

We used a qualitative descriptive design for this study, which was part of a large research series on older people with OA to maintain their physical function and QOL if they did not feel comfortable undergoing physicianrecommended TKA. A qualitative design was selected to better understand older adults' perceptions of weight control. Part of this work has been presented at the 27th European Congress of Psychiatry [23].

\section{Sample and setting}

We recruited older adults by convenience from one medical center and two regional hospitals in northwestern Taiwan. Physicians or nurses in outpatient orthopedic surgical clinics were asked to refer older adult patients with knee OA. Referred cases were included in the study by these criteria: 1 ) diagnosed with knee OA, 2) $\geq 55$ years old, 3 ) did not feel comfortable undergoing physician-recommended TKA, and 4) able to understand and speak in Mandarin Chinese. Outpatients were excluded for other comorbid conditions causing disability (e.g., stroke, gout, and rheumatoid arthritis).

\section{Data collection}

Participants' data were collected in one-on-one, face-toface, in-depth interviews using an interview guide (Table 1). The interview guide was developed by the research team and pilot tested in two older adult patients with knee OA. As a result of the participants' responses, no modification was made. Only the results of questions 7-9 were analyzed in this study. Interviews were audiotaped with participants' permission. Before interviews, participants' information was collected using a researcher-designed form for demographics (age, BMI, gender, education level, religious beliefs, marital status, number of children, and work status) and clinical information (time since osteoarthritis diagnosis, site of OA, current treatment for $\mathrm{OA}$, and experience of undergoing TKA). 
Table 1 Interview Guide

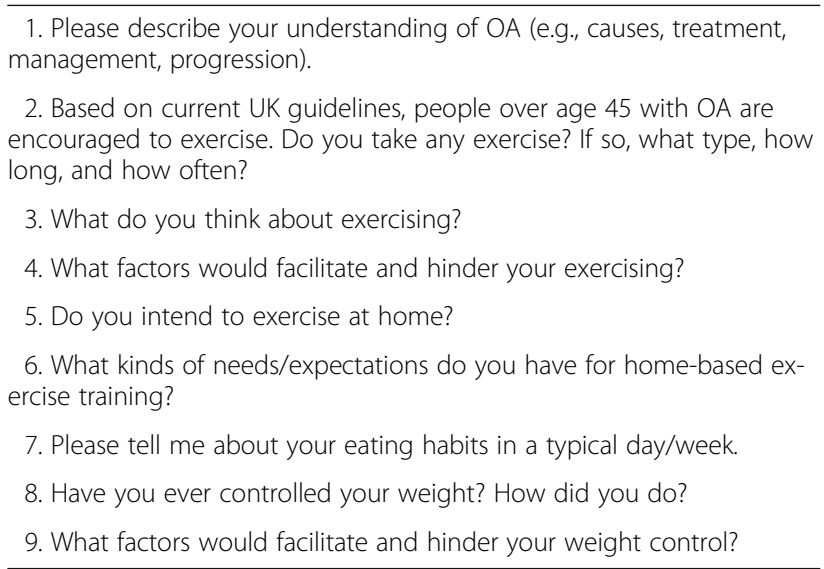

The research assistant (RA) who collected the data was an experienced, bachelor-prepared female nurse who was trained by working on our OA projects over 7 years. She collected data in audiotaped individual interviews, each lasting 20-60 min. The RA had no contact with eligible participants before recruitment. Participants were interviewed in Mandarin Chinese in a quiet room at participating hospitals; most participants were accompanied by their family. Immediately after each interview, The RA took field notes immediately after each interview to record observations about participants' emotions or behaviors during interviews. Data collection proceeded until analysis showed no new themes (data saturation) for each selected hospital.

\section{Ethical considerations}

This study was approved by the Institutional Review Board (IRB) of Chang Gung Medical Foundation (201601593B0), and the processes followed were in accordance with the ethical standards of the IRB and with the Helsinki Declaration of 1975, as revised in 1983. After IRB approval, physicians or nurses in outpatient orthopedic surgical clinics referred older adult patients with knee OA. The RA approached referred cases in each hospital's orthopedic department waiting room and determined if they met the study criteria. The RA described the study purpose, procedure, interview time, confidentiality and rights to refuse participation or to withdraw from the study at any time. After older outpatients with OA decided to participate, they signed a consent form. A gift about 5 US dollars was provided after completing the interview to thank participants for their time.

\section{Data analysis}

All audiotapes were transcribed verbatim within $48 \mathrm{~h}$ after interviews. Transcripts were analyzed by concept analysis [24]. First, the entire transcript and field notes for each participant were read and then reread several times to obtain a complete sense of the data. Next, all transcripts were analyzed to select and highlight significant phrases and statements. Data were then coded line by line. Finally, coded data were compared across transcripts to organize similar elements of experience, to identify emergent themes, and then frequency of each theme was counted. Before the study, the team had decided that each theme would be supported by at least $5 \%$ of the participants. Participants' demographic and clinical information were analyzed by descriptive statistics (frequencies, percentages, means, and standard deviations) using a computer for analysis with SPSS/PC for Window 23.0 statistical software.

\section{Rigor}

We established data trustworthiness by our extended engagement with transcripts, observing participants, peer debriefing, member checking and field notes [25]. For peer debriefing, the authors discussed the qualitative analysis with experts. For member checking, we asked three participants to review and check the validity of our findings. To ensure confirmability, the second author kept memos on decisions made throughout the study, thus allowing audit.

\section{Results}

\section{Characteristics of participants}

Of 131 older knee OA outpatients who met the study criteria, 11 declined to participate because of time constraints and two did not complete the interview related to weight control. The remaining 118 participants were on average 70.8 years old $(\mathrm{SD}=7.2$, range $=56-89)$. The majority was female $(67.8 \%)$, had graduated from primary school (55.9\%), had religious beliefs (95.8\%), was married (73.7\%), and had no job (83.9\%). Their average time since OA diagnosis was 55.5 months $(\mathrm{SD}=55.0$, range $=0-362$ ). The majority of participants had a Kellgren-Lawrence osteoarthritis classification of Stage IV (57.6\%). Only $25.4 \%$ had body weight in the normal range. About $8 \%$ had previously received TKA. For details, see Table 2.

\section{Weight-control strategies}

Over half of our participants $(n=66,55.9 \%)$ reported having controlled their weight. Their most common weight-control strategies were to control their diet and to combine exercise and diet control together (Table 3). Regarding diet control, the majority of participants tried to decrease the amount of food they ate. As P5 said, "I try to not eat so much. I used to eat all that I could. Now, I'm afraid of eating too much." Some participants tried to skip dinner or eat less at dinner. As P37 said, "Sometimes, I try to not eat dinner to lose weight. If I 
Table 2 Participants' characteristics $(N=118)$

\begin{tabular}{|c|c|}
\hline \multicolumn{2}{|l|}{ Characteristic } \\
\hline \multicolumn{2}{|l|}{ Gender } \\
\hline Male & $38(32.2)$ \\
\hline Female & $80(67.8)$ \\
\hline \multicolumn{2}{|l|}{ Body mass index } \\
\hline Normal & $30(25.4)$ \\
\hline Overweight & $38(32.2)$ \\
\hline Mild obesity & $35(29.7)$ \\
\hline Moderate obesity & $13(11.0)$ \\
\hline Severe obesity & $2(1.7)$ \\
\hline Age, years (range $=56-89)$ & $70.8(7.2)$ \\
\hline \multicolumn{2}{|l|}{ Education } \\
\hline Illiterate & $12(10.2)$ \\
\hline Primary school & $66(55.9)$ \\
\hline Junior high school & $18(15.3)$ \\
\hline Senior high school & $17(14.4)$ \\
\hline College and above & $5(4.2)$ \\
\hline \multicolumn{2}{|l|}{ Religious beliefs } \\
\hline Yes & $113(95.8)$ \\
\hline No & $5(4.2)$ \\
\hline \multicolumn{2}{|l|}{ Marital status } \\
\hline Single & $2(1.7)$ \\
\hline Married & $87(73.7)$ \\
\hline Divorced & $3(2.5)$ \\
\hline Widowed & $26(22.0)$ \\
\hline Number of children (range $=0-7$ ) & $3.4(1.2)$ \\
\hline \multicolumn{2}{|l|}{ Work status } \\
\hline Yes & $19(16.1)$ \\
\hline No & $99(83.9)$ \\
\hline Time since osteoarthritis diagnosis, months (range $=0-362$ ) & $55.5(55.0)$ \\
\hline \multicolumn{2}{|l|}{ Kellgren-Lawrence classification } \\
\hline Stage III & $50(42.4)$ \\
\hline Stage IV & $68(57.6)$ \\
\hline \multicolumn{2}{|l|}{ Site of osteoarthritis } \\
\hline Left knee & $39(33.1)$ \\
\hline Right knee & $52(44.1)$ \\
\hline Both knees & $27(22.9)$ \\
\hline \multicolumn{2}{|l|}{ Current treatment for osteoarthritis } \\
\hline Medication & $100(84.7)$ \\
\hline Rehabilitation & $3(2.5)$ \\
\hline Medication+ Rehabilitation & $15(12.7)$ \\
\hline \multicolumn{2}{|l|}{ Previously received total knee arthroplasty } \\
\hline Yes & $8(6.8)$ \\
\hline No & $110(93.2)$ \\
\hline
\end{tabular}

Continuous variables are presented by mean and standard deviation, with categorical variables presented by frequency and percentage feel hungry, I drink water. I think eating dinner is the main reason for gaining weight. For weight control, I eat less at dinner." Some participants decreased the amount of fat in their diet. In extreme cases, they even became vegetarians. As P7 said, "It's easy to gain weight during holidays. In the mid-autumn festival, we need to pray using moon cakes. If you eat moon cakes, you will quickly gain weight. Therefore, I replaced moon cakes with fruits or cookies. Similarly, we need to pray in the Chinese New Year. I eat vegetarian pig, chicken, and fish [made from tofu]. I eat almost only vegetables and fruits now. All are very light."

In addition, some participants combined diet control and exercise to control their weight. As P119 said, "I climb a mountain every Tuesday. It takes about 4 hours. I always weigh myself every day. I control my weight by dietary control and exercise." Similarly, P15 said, "I use dietary control and exercise to control my weight. I try to decrease the amount of food I eat and walk half an hour per day."

\section{Facilitators of weight control}

Participants' weight control was facilitated by a desire for good health, wanting to improve their walking ability or mobility, perceiving that they had gained weight, wanting to look good, and advice from healthcare providers (Table 3). Regarding the desire for good health, some participants said that losing weight was a way to manage their other chronic diseases. As P46 said, "I have diabetes and hypertension. I need to cut down the amount of rice. To control these conditions, I must eat less and exercise." However, some participants simply wanted to have good health. As P114 said, "I want to live longer, so I will maintain my good health."

Some participants expressed having difficulty walking or/and with mobility. As P20 said, "I think that controlling weight might help me with walking. If I wasn't so fat, it would be easier for me to walk and move around." Similarly, P65 said, "Being overweight makes it difficult for me to walk. Moreover, it [being overweight] makes me feel short of breath."

Regarding their perception of having gained weight, some participants monitored their weight by weighing themselves. As P70 said, "I weigh myself every day. If I gain weight, then I eat less." Some participants used personal methods to guess their weight. As P104 said, "I enjoy eating, especially sweet snacks. That's why I'm so fat. If I eat more snacks, I know I have gained weight and should eat less for the next couple of days."

Wanting to look good was a common theme for older women. As P32 said, "I'm very careful about my appearance. I want to look good. You see, I'm already over 80 , but I still dye my hair. Being overweight looks bad." Similarly, P90 said, "I love beautiful things. However, my 
Table 3 Main findings

\begin{tabular}{ll}
\hline & Themes \\
\hline Weight-control strategies & - Control diet $(n=51)$ \\
Facilitators of weight control & - Exercise and control diet together $(n=15)$ \\
& - A desire for good health $(n=45)$ \\
& - Wanting to improve walking ability or mobility $(n=37)$ \\
& - Perceiving that one had gained weight $(n=34)$ \\
& - Wanting to look good $(n=11)$ \\
& - Advice from healthcare providers $(n=9)$ \\
Barriers to weight control & - Perceiving that dietary control was not needed $(n=36)$ \\
& - Difficulty controlling appetite $(n=10)$ \\
& - Dietary control was difficult $(n=7)$ \\
& - Not eating caused physical discomfort $(n=7)$
\end{tabular}

husband said my taste has become worse. I replied that it was due to my weight; no matter what I wear, it looks bad. Then I start to control my weight."

As for the facilitator of healthcare providers' reminder to control weight, P35 said, "My doctor told me that I'm overweight, increasing my risk for surgery. To have TKA, I need to lose some weight." Similarly, P86 said, "I recently had a health examination. My doctor reminded me that my blood sugar is slightly high, so I need to control my weight and diet."

\section{Barriers to weight control}

Over $40 \%$ of participants said that they did not have any barriers to weight control. The remaining participants described the following barriers to weight control: perceiving that dietary control was not needed, difficulty controlling appetite, dietary control was difficult, and not eating caused physical discomfort (Table 3). Participants' perceptions of not needing to control their weight was based on three reasoning/perception patterns: 1) they ate regularly, 2) weight was normal or below normal, and 3) they were too old. For the first pattern, P27 said, "I eat the same amount of food [each day] and very regularly. So, I don't need to control my weight." For the second pattern, P9 (a mildly obese participant) said, "I tend to be underweight. I don't need to control my weight." For the third pattern, P80 said, "I am old and don't need to care about my appearance. I don't think about controlling my weight."

Regarding the barrier of difficulty controlling appetite, P61 said, "When I see food, I can't control myself. I must eat it. Otherwise, I feel sorry for myself." Several participants said weight control was difficult. As P74 said, "I don't know what's wrong. I eat as other people recommend. However, they lose weight, but I don't. Sometimes, I even gain more weight. I really don't know how to control my weight." Some participants said that not eating caused physical discomfort, e.g., dizziness, stomach pains, hunger, and trouble sleeping. As P20 said, "If I don't eat, I feel drowsy and dizzy. Sometimes, my hunger prevents me from sleeping."

\section{Discussion}

Our results contribute to the literature on OA and nutrition by describing weight-control strategies, facilitators of and barriers to weight control among older adults with knee OA who did not feel comfortable undergoing physician-recommended TKA. In addition, our findings provide insights to clinicians caring for older overweight adults waiting for knee-replacement surgeries in countries with waiting lists. These results also contribute to OA and nutrition research in Taiwan, thus expanding related knowledge from western countries. The major strengths of this study are its large sample, particularly for a qualitative study, and the research team's long engagement with older adults, which allowed them to gain their trust in collecting data on sensitive topics such as weight control and choosing to not undergo kneereplacement surgery. The study's weaknesses are outlined in the limitations below.

Speaking to weight control, fewer than $60 \%$ of participants had controlled their weight even though only about $1 / 4$ weighed in the normal range. Moreover, even though controlling diet was their most common strategy for controlling weight, their methods may have placed them in a malnourished condition. For example, participants said they decreased the amount of food they ate, but they had difficulty describing the exact amount of food and its calories. This eating behavior could result in their eating high-calorie foods or snacking between meals but being unaware of the problem. These adults, like all adults with knee OA, should be educated about healthy eating [9]. A healthy diet emphasizes fruits, vegetables, whole grains, and fat-free or low-fat milk and milk products; it includes lean meats, poultry, fish, beans, eggs, and nuts; is low in saturated fats, trans fats, cholesterol, sodium, and added sugars; and stays within a person's daily caloric needs [26].

Participants' perceptions of exercise were vague. Many participants described taking a walk as their exercise. They commonly took a 20- to 30-min walk around a park near their home. However, OA patients are recommended to perform $30 \mathrm{~min}$ of moderate-intensity 
physical activity at least 5 times a week, or 150 min per week [27]. If taking a walk can be counted as moderateintensity physical activity, each case should be carefully examined.

Our participants described weight control as being facilitated by desiring good health, wanting to improve walking or mobility, perceiving that they had gained weight, wanting to look good, and advice from healthcare providers. Desiring good health as a facilitator of weight control can be explained by the association of overweight and obesity with various chronic diseases [28], such as type 2 diabetes. Our second facilitator of weight control (to improve walking/mobility) is consistent with reports that US patients with knee OA were motivated to lose weight because they wanted to improve their knee symptoms (e.g., pain) [29] and that caregivers of knee OA patients in Taiwan identified knee pain as a main barrier to patients' walking and mobility [30]. Another facilitator of weight control in our study was a perceived weight gain. Some participants regularly weighed themselves, but some just made a guess. Regularly weighing oneself is important for weight control [9] and should be emphasized in weight-control intervention programs. Our finding that physical appearance was a common motivator for weight loss is consistent with a report of US patients before and after TKA [29]. Finally, we found that weight control was facilitated by advice from healthcare providers. Our finding differs from the conclusion of a systematic review that primary care clinicians in various western countries had personal beliefs about patient adherence and treatment effectiveness that made them reluctant to recommend standard treatment to OA patients [31]. As a result, their advice did not help patients. Thus far, no studies have examined this issue in Asian countries. Future Asian studies should explore the role of health care providers in providing advice to OA patients.

About $45 \%$ of our older participants did not describe any barriers to weight control. Since no other studies have reported this finding, no comparison can be made. A majority of our remaining participants perceived that dietary control was not needed. Under this barrier to weight control, participants' descriptions of not needing weight control was based on three reasoning/perception patterns. First, participants perceived that they ate regularly and did not need to control their weight. However, as people age, their metabolic rate decreases leading to their gaining weight. These patients should be educated on this issue. Second, participants perceived their body weight was normal (even underweight) and did not need to be controlled. Clinicians should not only advise OA patients to weigh themselves regularly, but also emphasize the importance of calculating one's BMI. Patients must be taught the meaning of BMI rather than only body weight. Third, participants perceived they were too old and did not need to control their weight. These patients need to be informed of medical and technological advances that have increased their life expectancy. Weight control is not only related to appearance but may also promote one's QOL.

We also found that a barrier to weight control was difficulty controlling appetite, echoing a report that that obese knee OA patients in the UK perceived overconsuming food as a barrier to healthy eating [13]. In addition, our participants described weight loss as difficult to achieve and maintain, as reported for older adults with knee OA in Australia [10]. Another barrier to weight control described by our participants was that not eating caused discomfort, which might be due to low blood sugar.

Some barriers to weight control identified in other studies, e.g., lack of motivation [11], pain in the knee joint [11], pain in other joints [11], problems with calorie counts and food intake record [12], not preparing meals by oneself [12], lack of time for eating [12], desiring high-fat/high-calorie foods [13], and managing mood [13], were not themes in our study. As we described above, one facilitator of our participants' weight control was to improve walking and mobility [30], which might have been hindered by knee pain. In addition, all our participants were older adults, and most did not work. They might have had more time to prepare and eat food. They also did not feel stressed to consume more food. Interestingly, none of our participants expressed having difficulty counting calories in their food even though they did not know how to do it. This issue suggests a lack of knowledge about calories.

Based on our findings, we have some suggestions for practice and research. Regarding practice, patients with knee OA should first be encouraged to weigh themselves every day and taught about using BMI to examine their body weight. Second, these patients should consult regularly with a dietician, who can teach them about measuring calories, healthy eating, and meal-exchange lists. Third, health care providers should be aware of different patterns of not perceiving a need for weight control and teach these patients the appropriate knowledge to overcome their barriers. Regarding research, we first suggest that the role of health care providers in Asian countries should be explored in providing advice to OA patients. Second, the role of barriers to weight control identified in other studies but not identified by our participants. Should be explored in the weight control of Asian OA patients.

Our findings may be limited by our study using a qualitative descriptive design. Although a descriptive design is useful for understanding participants' experiences, it is less rigorous than other qualitative designs, 
such as grounded theory. In addition, older adults who agreed to participate may have had different characteristics from those who rejected participation. Since we are not allowed access to data on nonparticipants, we cannot make comparisons.

\section{Conclusion}

We found that only $25.4 \%$ of participants with knee OA had body weight in the normal range even though 55.9\% described having controlled their weight. Their most common weight control strategies were to control diet and to exercise and control diet together. Their weight control was facilitated by desiring good health, wanting help with walking or mobility, perceiving that they had gained weight, wanting to look good, and advice from healthcare providers. Common barriers to weight control were perceiving that dietary control was not needed, difficulty controlling appetite, difficulty controlling diet, and not eating caused physical discomfort. Health care providers can integrate these identified facilitators and barriers into a weight-control intervention program to help their patients who did not feel comfortable undergoing physician-recommended TKA to control their weight. Furthermore, the importance of weighing oneself every day, the meaning of BMI, consulting with a dietician regularly to control weight, and providing appropriate knowledge about aging and weight control should also be included in any weight-control intervention program.

\section{Supplementary information}

Supplementary information accompanies this paper at https://doi.org/10. 1186/s12891-020-03480-2.

Additional file 1. COREQ (Consolidated criteria for Reporting Qualitative research) Checklist.

\section{Abbreviations}

OA: Osteoarthritis; BMl: Body mass index; QOL: Quality of life; TKA: Total knee arthroplasty; RA: Research assistant; IRB: Institutional Review Board

\section{Acknowledgements}

We thank all participants for taking the time to share their experiences. In addition, we acknowledge that part of this work has been presented at the 27th European Congress of Psychiatry.

\section{Authors' contributions}

WLY assisted with designing the study, collecting and analyzing the data, and writing the manuscript. YFT designed the study, obtained funding, supervised the data collection, analyzed the data, and wrote the manuscript. KYH, DWC, JSW, and CYC assisted with collecting and analyzing the data, as well as writing the manuscript. All authors read and approved the final manuscript.

\section{Funding}

This research was supported by the Ministry of Science and Technology, Taiwan (MOST 106-2314-B-182-010-MY3). The funder had no role in the design of the study, collection, analysis and interpretation of data or writing the manuscript.

\section{Availability of data and materials}

The datasets used and/or analysed during the current study are available from the corresponding author on reasonable request.

\section{Ethics approval and consent to participate}

This study was approved by the institutional review board of Chang Gung Medical Foundation (201601593B0). All participants gave their written consent to participate in this study.

Consent for publication

Not applicable.

\section{Competing interests}

The authors declare that they have no conflicts of interest.

\section{Author details}

'Department of Traumatology Orthopedics, Chang Gung Memorial Hospital at Linkou, Tao-Yuan, Taiwan. ${ }^{2}$ College of Medicine, Chang Gung University, Tao-Yuan, Taiwan. ${ }^{3}$ School of Nursing, College of Medicine, Chang Gung University, Tao-Yuan, Taiwan. ${ }^{4}$ Department of Nursing, Gung University of Science and Technology, Tao-Yuan, Taiwan. ${ }^{5}$ Department of Psychiatry, Chang Gung Memorial Hospital at Keelung, Keelung, Taiwan. ${ }^{6}$ Department of Orthopedic Surgery, Chang Gung Memorial Hospital at Linkou, Tao-Yuan, Taiwan. ${ }^{7}$ Division of Joint Reconstruction, Department of Orthopedic Surgery, Chang Gung Memorial Hospital at Keelung, Keelung, Taiwan. ${ }^{8}$ Healthy Aging Research Center, Graduate Institute of Rehabilitation Science, Chang Gung University, Tao-Yuan, Taiwan. ${ }^{9}$ Heart Failure Center, Department of Physical Medicine and Rehabilitation, Chang Gung Memorial Hospital at Keelung, Keelung, Taiwan.

Received: 25 August 2019 Accepted: 6 July 2020

Published online: 02 August 2020

\section{References}

1. Cross M, Smith E, Hoy D, Nolte S, Ackerman I, Fransen M, et al. The global burden of hip and knee osteoarthritis: estimates from the global burden of disease 2010 study. Ann Rheum Dis. 2014;73:1323-30. https://doi.org/10. 1136/annrheumdis-2013-204763.

2. GBD 2017. Disease and Injury Incidence and Prevalence Collaborators. Global, regional, and national incidence, prevalence, and years lived with disability for 354 diseases and injuries for 195 countries and territories, 1990-2017: a systematic analysis for the Global Burden of Disease Study 2017. Lancet. 2018;392:1789-858. https://doi.org/10.1016/S01406736(18)32279-7.

3. de Rooij M, van der Leeden M, Heymans MW, Holla JF, Häkkinen A, Lems WF, et al. Prognosis of pain and physical functioning in patients with knee osteoarthritis: a systematic review and meta-analysis. Arthritis Care Res. 2016:68481-92. https://doi.org/10.1002/acr.22693.

4. Oliveria SA, Felson DT, Cirillo PA, Reed JI, Walker AM. Body weight, body mass index, and incident symptomatic osteoarthritis of the hand, hip, and knee. Epidemiology. 1999;10:161-6.

5. Stürmer T, Günther KP, Brenner H. Obesity, overweight and patterns of osteoarthritis: the Ulm osteoarthritis study. J Clin Epidemiol. 2000;53:307-13. https://doi.org/10.1016/S0895-4356(99)00162-6.

6. Felson DT, Naimark A, Anderson J, Kazis L, Castelli W, Meenan RF. The prevalence of knee osteoarthritis in the elderly. The Framingham Osteoarthritis Study. Arthritis Rheum. 1987;30:914-8. https://doi.org/10.1002/ art.1780300811.

7. Miller GD, Rejeski WJ, Williamson JD, Morgan T, Sevick MA, Loeser RF, et al. The Arthritis, diet and activity promotion trial (ADAPT): design, rationale, and baseline results. Control Clin Trials. 2003;24:462-80. https://doi.org/10. 1016/S0197-2456(03)00063-1

8. Christensen $\mathrm{R}$, Bartels EM, Astrup A, Bliddal $H$. Effect of weight reduction in obese patients diagnosed with knee osteoarthritis: a systematic review and meta-analysis. Ann Rheum Dis. 2007;66:433-9. https://doi.org/10.1136/ard. 2006.065904.

9. National Institute for Health and Clinical Excellence. Osteoarthritis: care and management in adults. https://www.nice.org.uk/guidance/cg177 (2014). Accessed 20 August 2019.

10. Ekram AR, Cicuttini FM, Teichtahl AJ, Crammond BR, Lombard CB, Liew SM, et al. Weight satisfaction, management strategies and health beliefs in knee 
osteoarthritis patients attending an outpatient clinic. Intern Med J. 2016;46: 435-42. https://doi.org/10.1111/imj.13007.

11. Howarth D, Inman D, Lingard E, McCaskie A, Gerrand C. Barriers to weight loss in obese patients with knee osteoarthritis. Ann R Coll Surg Engl. 2010; 92:338-40. https://doi.org/10.1308/003588410X12628812458653.

12. Aree-Ue S, Saraboon Y, Belza B. Long-term adherence and effectiveness of a multicomponent intervention for community-dwelling overweight Thai older adults with knee osteoarthritis: 1-year follow up. J Gerontol Nurs. 2017;43:40-8. https://doi.org/10.3928/00989134-20170111-09.

13. Pellegrini CA, Ledford G, Chang RW, Cameron KA. Understanding barriers and facilitators to healthy eating and physical activity from patients either before and after knee arthroplasty. Disabil Rehabil. 2018;40:2004-10. https:// doi.org/10.1080/09638288.2017.1323026.

14. Bruyère $\mathrm{O}$, Honvo G, Veronese $\mathrm{N}$, Arden NK, Branco J, Curtis EM, et al. An updated algorithm recommendation for the management of knee osteoarthritis from the European Society for Clinical and Economic Aspects of osteoporosis, osteoarthritis and musculoskeletal diseases (ESCEO). Semin Arthritis Rheum. 2019;49:337-50. https://doi.org/10.1016/j.semarthrit.2019.04. 008.

15. Parsons GE, Godfrey H, Jester RF. Living with severe osteoarthritis while awaiting hip and knee joint replacement surgery. Musculoskeletal Care. 2009;7:121-35. https://doi.org/10.1002/msc.145.

16. Beswick AD, Wylde V, Gooberman-Hill R, Blom A, Dieppe P. What proportion of patients report long-term pain after total hip or knee replacement for osteoarthritis? A systematic review of prospective studies in unselected patients. BMJ Open. 2012;2:e000435. https://doi.org/10.1136/bmjopen-2011000435

17. Blom AW, Artz N, Beswick AD, Burston A, Dieppe P, Elvers KT, et al. Improving patients' experience and outcome of total joint replacement: the RESTORE programme. NIHR Journals Library; 2016. https://doi.org/10.3310/ pgfar04120.

18. Mahdi A, Svantesson M, Wretenberg P, Hälleberg-Nyman M. Patients' experiences of discontentment one year after total knee arthroplasty- a qualitative study. BMC Musculoskelet Disord. 2020;21:29. https://doi.org/10. 1186/s12891-020-3041-y.

19. Fransen M, McConnell S, Harmer AR, Van der Esch M, Simic M, Bennell KL. Exercise for osteoarthritis of the knee: a Cochrane systematic review. $\mathrm{Br}$ J Sports Med. 2015:49:1554-7. https://doi.org/10.1136/bjsports-2015-095424.

20. Alrushud AS, Rushton AB, Kanavaki AM, Greig CA. Effect of physical activity and dietary restriction interventions on weight loss and the musculoskeletal function of overweight and obese older adults with knee osteoarthritis: a systematic review and mixed method data synthesis. BMJ Open. 2017;7: e014537. https://doi.org/10.1136/bmjopen-2016-014537.

21. Loeser RF, Beavers DP, Bay-Jensen AC, Karsdal MA, Nicklas BJ, Guermazi A, et al. Effects of dietary weight loss with and without exercise on interstitia matrix turnover and tissue inflammation biomarkers in adults with knee osteoarthritis: the intensive diet and exercise for Arthritis trial (IDEA). Osteoarthr Cartil. 2017;25:1822-8. https://doi.org/10.1016/j.joca.2017.07.015.

22. Smith KC, Losina E, Messier SP, Hunter DJ, Chen AT, Katz JN, et al. Budget impact of funding an intensive diet and exercise program for overweight and obese patients with knee osteoarthritis. ACR Open Rheumatol. 2020;2: 26-36. https://doi.org/10.1002/acr2.11090.

23. Tsai, YF, Yeh WL. Perceptions of weight control among older adults with knee osteoarthritis. Poster Presentation at the 27th European Congress of Psychiatry. 2019. https://www.morressier.com/article/07\%2D\%2

Dperceptions-weight-control-among-older-adults-knee-osteoarthritis/5c642 bec9ae8fb00131cf6ed. Accessed 2 July 2020

24. Berelson B. Content analysis in communication research. New York: Free Press; 1952.

25. Lincoln YS, Guba EG. Naturalistic inquiry. Beverly Hills, CA: Sage; 1985.

26. U.S. Department of Health and Human Services. Aim for a Healthy Weight. 2010. http://www.nhlbi.nih.gov/files/docs/public/heart/AlM_Pocket_Guide_ tagged.pdf. Accessed 20 Aug 2019.

27. Centers for Disease Control and Prevention. Physical Activity for Arthritis 2016. http://www.cdc.gov/arthritis/basics/physical-activity-overview.html. Accessed 20 Aug 2019

28. Meigs JB, Wilson PW, Fox CS, Vasan RS, Nathan DM, Sullivan LM, et al. Body mass index, metabolic syndrome, and risk of type 2 diabetes or cardiovascular disease. J Clin Endocrinol Metab. 2006;91:2906-12. https://doi. org/10.1210/jc.2006-0594
29. Pellegrini CA, Ledford G, Hoffman SA, Chang RW, Cameron KA. Preferences and motivation for weight loss among knee replacement patients: implications for a patient-centered weight loss intervention. BMC Musculoskelet Disord. 2017;18:327. https://doi.org/10.1186/s12891-017-1687$x$.

30. Hsu KY, Tsai YF, Lin YP, Liu HT. Primary family caregivers' observations and perceptions of their older relatives' knee osteoarthritis pain and pain management: a qualitative study. J Adv Nurs. 2015;71:2119-28. https://doi. org/10.1111/jan.12684

31. Egerton T, Diamond LE, Buchbinder R, Bennell KL, Slade SC. A systematic review and evidence synthesis of qualitative studies to identify primary care clinicians' barriers and enablers to the management of osteoarthritis. Osteoarthr Cartil. 2017;25:625-38. https://doi.org/10.1016/j.joca.2016.12.002.

\section{Publisher's Note}

Springer Nature remains neutral with regard to jurisdictional claims in published maps and institutional affiliations.
Ready to submit your research? Choose BMC and benefit from:

- fast, convenient online submission

- thorough peer review by experienced researchers in your field

- rapid publication on acceptance

- support for research data, including large and complex data types

- gold Open Access which fosters wider collaboration and increased citations

- maximum visibility for your research: over $100 \mathrm{M}$ website views per year

At $\mathrm{BMC}$, research is always in progress.

Learn more biomedcentral.com/submissions 